\title{
Go the whole nine yards? How extent of meat restriction impacts individual dietary experience
}

\author{
Kathryn E. Asher ${ }^{a 1}$ and Paul Peters ${ }^{b}$ \\ ${ }^{a}$ Department of Sociology, University of New Brunswick \\ ${ }^{\mathrm{b}}$ Department of Health Sciences, Carleton University
}

\section{Highlights}

- A third of American adults self-identify as reducing their meat consumption.

- One percent of the American adult population identifies as a vegetarian.

- A vegetarian diet had the strongest lived dietary experiences.

- The degree and type of meat restriction impacts lived dietary experiences.

\begin{abstract}
There are a variety of approaches to addressing meat overconsumption including forms of meat restriction that vary by the degree of reductions and the type of meat reduced. This study examines three such diets - a vegetarian diet, a reducedmeat diet, and a chicken-free diet-with a focus on the differences in the lived dietary experiences of their adherents. These lived experiences are operationalized using a variety of measures: satisfaction with food-related life, social ties, convenience, social/personal life, health, cost, motivation, identity, perception of prevalence rates, length of diet adherence, and the theory of planned behavior (intentions, attitudes, perceived behavioral control, and subjective norms). The data comes from an online survey of a cross-sectional, census-balanced sample of more than 30,0000 U.S. residents aged 18+ years sourced from Nielsen's Harris Panel. The results showed meat reducers to be a larger group than previously suspected, with a third of American adults self-identifying as reducing their meat consumption, compared to one percent each who identify as a vegetarian or chicken avoider. The findings also demonstrated that a vegetarian diet had the strongest lived dietary experiences among American adults who are currently eating one of the meat-restricted diets. This research speaks to how the degree and type of meat restriction can impact an individual's lived experience with their diet.
\end{abstract}

\section{Keywords}

vegetarian; meat reduction; chicken avoidance; sociology of food; dietary experiences

\footnotetext{
${ }^{1}$ Corresponding author: Dr. Kathryn Asher, Department of Sociology, University of New Brunswick, PO Box 4400, Fredericton, New Brunswick, Canada, E3B 5A3, kathryn.asher@unb.ca.
} 


\section{Introduction}

Meat has long dominated the American plate thanks to its prized position in U.S. culture atop the food hierarchy (Twigg, 1983). Increasingly, however, meat's role in U.S. society is being critiqued and efforts to limit meat consumption are permeating social culture. The practice of meat restriction has a long history. In the fifth century BCE, Pythagoras attributed his meat abstention to a belief that upon death human souls could transmigrate into animals (DeMello, 2012, p. 35). In more recent times, scholars and writers have offered other arguments for why meat should be avoided and farmed animals protected from human harm. Some writers and philosophers have put forth theories related to speciesism (Dunayer, 2004; Singer, 1990) and moral rights (Regan, 1983), while other arguments have focused on physical harm (Robbins, 2001; Safran Foer, 2009; Singer \& Mason, 2006) or animals' intelligence and emotional capabilities (Hatkoff, 2009; Moussaieff Masson, 2003).

Public discourse and literature has also emphasized human health promotion as a reason to decrease meat consumption. The Academy of Nutrition and Dietetics (2016) has cited meat-free diets as having a variety benefits for disease prevention in areas including cancer, heart disease, hypertension, and type 2 diabetes. Likewise, the cost of treatment for meat and dairy-related cancers, diabetes, and heart disease cases in the U.S. is thought to be around $\$ 314$ billion annually, representing three-fifths of Medicare spending in the U.S. (Simon, 2013).

Environmental concerns are also increasingly cited. The United Nations listed animal agriculture as one of the top causes of the most severe environmental threats when it comes to issues of "land degradation, climate change and air pollution, water shortage and water pollution and loss of biodiversity" (Food and Agriculture Organization of the United Nations, 2006, p. xx). Researchers have pointed to meatless diets as having far less impact on the environment compared to diets containing meat and other animal foods (Eshel, Martin, \& Bowen, 2010, p. 1; Marlow et al., 2009, p. 1699S; Pimentel \& Pimentel, 2003, p. 660S; Reijnders \& Soret, 2003, p. 664S).

In addition to concerns about animal protection, health, and the environment, other common concerns include human hunger relief (Chiu \& Lin, 2009; Lewis, 1994) and social justice motivations such as the link between the oppression of human and nonhuman animals (Nibert, 2002), including issues of gender equality (Adams, 2004), labor (Dillard, 2008; Human Rights Watch, 2004; Oxfam America, 2015), and income and racial disparities (DeMello, 2012).

\subsection{Meat-restricted diets}

There are a variety of approaches to addressing meat overconsumption including forms of meat restriction that vary by the degree of reductions and the type of meat reduced. This study examines three such diets-a vegetarian diet, $^{2}$ a reducedmeat diet, and a chicken-free diet-with a focus on how the lived dietary experiences of their adherents differ. While the literature offers an in-depth understanding of the experiences of vegetarians (Asher \& Cherry, 2015; Cherry, 2015; Hirschler, 2011; Jabs, Sobal, \& Devine, 2000; Ruby, 2012), far less is known about the experiences of meat

\footnotetext{
${ }^{2}$ Vegetarianism is being used herein as a shorthand for a meat-free diet and so includes veganism (a diet that additionally excludes eggs, dairy, and other animal products).
} 
reducers and omnivores who eschew chicken (particularly non-pescetarians) or about how these diets compare to one another.

A chicken-free diet is of interest for these purposes because of a concern about smaller-bodied animals given that a greater number of chickens are needed to produce the same quantity of meat from cows and pigs. As Messina (2011) explains, it takes 220 chickens to yield the same amount of meat as found in one cow used for beef. Indeed, concerns about smaller-bodied animals is not new. As early as the 1990s, Singer cautioned against consuming mollusks even given the scientific uncertainty about their ability to experience pain, because doing so harm "a considerable number of creatures" (1990, p. 174). More recently, others have addressed the matter including MacClellan who argues that "animal size is a relevant and unappreciated consideration in moral evaluations of killing animals for food, especially for utilitarians" (2013, p. 57). Effective altruists such as Tomasik (2007) have also noted that "eating certain types of meat may cause more suffering than eating the same amount of another type of meat under otherwise identical circumstances."

\subsection{Current study}

Eating is not only an individual endeavour but a social activity (Paisley, Beanlands, Goldman, Evers, \& Chappell, 2008, p. 80) and so this study focuses on the lived dietary understandings of those currently eating one of the three meat-restricted diets under study. The study explores a central research question: does the degree and type of meat restriction impact an individual's lived experience with their diet? The study answers this question by drawing data from an online U.S. sample. Lived experiences are operationalized using a variety of measures: satisfaction with food-related life, social ties, convenience, social/personal life, health, cost, motivation, identity, perception of prevalence rates, length of diet adherence, and the theory of planned behavior (intentions, attitudes, perceived behavioral control, and subjective norms). These measures are informed by the sociology of food (Germov \& Williams, 2008), which offers a solid theoretical grounding to analyze the social aspects of meat-free and meat-reduced diets (Beardsworth \& Keil, 1992; Fox \& Ward, 2008; Haverstock \& Forgays, 2012).

\section{Methods}

\subsection{Sample}

Data collection was carried out by administering an online survey to a crosssectional, census-balanced sample of U.S. residents 18+ years of age sourced through Nielsen's Harris Panel. ${ }^{3}$ Nielsen invited panelists from their sample as well as members of its third-party panel providers to participate by providing a link to the online survey. The sample was selected by Nielsen based on the demographic characteristics of potential invitees to ensure the sample was as close to census-balanced as possible, which was based on non-interlocking quotas for age by sex, region, race/ethnicity, education, and household income. The data relayed here was collected as part of a larger study conducted during October and November 2016 (Asher, 2016a).

\footnotetext{
${ }^{3}$ Nielsen was not responsible for any survey design, data analysis, or reporting.
} 
More than 30,0000 respondents were screened. The survey was programmed and hosted on Qualtrics' online survey platform using the University of New Brunswick's license. All vegetarians and chicken avoiders proceeded to the full survey. To avoid oversampling meat reducers, only a proportion were randomly assigned to continue, which was done using Qualtrics' randomization function.

\subsection{Diet groups}

For these purposes, the three diets under study are defined as follows: 1) A vegetarian diet does not include any meat i.e., it excludes beef, pork, chicken, turkey, fish, shellfish, and other meats. A vegan diet is included in this definition because it is also meat-free; 2) A reduced-meat diet is followed by people who are reducing the total amount of meat they eat compared to a past diet, where the term "meat" includes any of the following: beef, pork, chicken, turkey, fish, shellfish, and other meats; and 3) A chicken-free diet excludes chicken but does include meat of some kind, i.e., includes beef, pork, turkey, fish, shellfish, and/or other meats.

When possible, a two-step verification process-based on a food frequency questionnaire and identification with the diet label-was used to classify individuals as currently eating one of these diets. This was done to avoid a scenario in which selfidentifying with the label leads to overestimates where individuals who consume meat are included among vegetarians (Juan, Yamini, \& Britten, 2015, p. 86). Respondents were asked to self-identify as meat reducers rather than basing this on self-reported food consumption. For more information on how respondents were screened see Asher, 2016a.

\subsection{Pilot testing}

Prior to data collection, the survey instrument was piloted in two ways. The first was through in-person cognitive interviewing with a convenience sample. The second method was a field test that directly tested the online survey with a sample of the target population provided by Nielsen.

\subsection{Ethical protocols}

The research was reviewed by the Research Ethics Board of the University of New Brunswick for its compliance with the TCPS2 2014 Tri-Council Policy Statement: Ethical Conduct for Research Involving Humans (Canadian Insitutes of Health Research, Natural Sciences and Engineering Research Council of Canada, \& Social Sciences and Humanities Research Council of Canada, 2014) and the University Policy on Research Involving Humans (University of New Brunswick, 2011). It is on file as REB \#2016-080.

\subsection{Data cleaning and analysis}

Analyses were conducted using IBM's Statistical Package for the Social Sciences (SPSS), Version 24. The dataset was downloaded in SPSS format from the Qualtrics survey platform. The data was weighted by Nielsen to ensure appropriate census-balancing for the U.S. adult population.

As a transparency measure to guard against publication bias (Christensen, 2016, pp. 5-6), the analyses in this study were based on a pre-analysis plan preregistered on publicly available pages on the Center for Open Science's Open Science Framework, which also houses the study's materials, survey instrumentation, datasets, and statistical code (see Asher, 2016a and Asher, 2016b). The pre-analysis 
plan was meant to serve as a rough framework for how the data was expected to be approached. The plan noted the possibility of changes (minor or major) once the analysis began and there were several instances were deviations from the plan were needed, which have been documented elsewhere (Asher, 2016a).

A variety of data cleaning measures were undertaken (both in real-time and following data collection) to remove data that added error or bias to the dataset. Full incompletes (considered to be unit nonresponse if the screener was not completed) were removed from the dataset because every question in the screener was deemed necessary to ensure a respondent qualified for inclusion in the study. Available-case analysis was used, which concerns only the respondents with complete data for variables of interest.

Certain types of terminations were conducted in real time during the screener. This entailed removing respondents who: 1) indicated they were under 18 years of age; 2) provided inconsistent answers to the diet verification questions; 3) failed the affirmation check after the instructional manipulation check (IMC) $\left.;{ }^{4} 4\right)$ had an unusually fast completion time for the screener (i.e., speeders); and 5) were in an over-quota demographic group. Prior to analysis, respondents with duplicate identification numbers were removed, as were respondents who did not have one.

\section{Measures}

\subsection{Food frequency questionnaire}

A food frequency questionnaire (FFQ) inquiring about the frequency of consumption of beef, pork, chicken, turkey, fish, shellfish, and other meats was administered to participants. Its frequency scale was based loosely on the Block Meat FFQ for Adults (NutritionQuest, n.d.). Several examples for each category in the food list were offered as memory cues. Instructions were used to help prompt accurate recall and to encourage respondents to take their time and carefully consider their response given that the question was thought to be prone to memory problems (Groves et al., 2009, p. 229). The reference period was "current diet," which differs by person as opposed to being a fixed timeframe such as the past week, month, year, etc.

\subsection{Satisfaction with food-related life}

Participants indicated their satisfaction with their food-related life using five items on a 1 (strongly disagree) to 5 (strongly agree) scale related to: finding food and meals to be negative elements in one's life; being generally displeased with food; getting satisfaction from food and meals in daily life; life in relation to food and meals

\footnotetext{
${ }^{4}$ Attention checks or IMCs can be used to identify inattentive respondents on self-administered surveys to address quality issues (Berinsky, Margolis, \& Sances, 2014, p. 739). One such question was used as the last question of the screener, with wording loosely based on the work of Belinsky, Margolis, \& Sances (2014). Those who failed this IMC as well as an additional check (a double fail) were not permitted to proceed given that respondent quality can be an issue with online panel respondents.
} 
being close to one's ideal; and conditions of one's life being excellent with regard to food.

This item is based on the satisfaction with food-related life (SWFL) scale from Grunert, Dean, Raats, Nielsen, and Lumbers (2007), where they tested seven items on a sample of European seniors, which later resulted in a five-item scale (Grunert et al., 2007 , pp. 488 \& 490). The scale has been administered to other demographic segments including a university sample (Schnettler et al., 2015). Some adjustments were made, including adding reverse wording to two of the items and using a 5-point Likert scale instead of a 7-point one to be consistent with other scales used in the survey. A reliability analysis with the five items from the SWFL scale was run giving a Cronbach's $a=0.72$, which indicates good reliability (Field, 2009, pp. 675 \& 679). There were no items that if deleted would have increased the scale's reliability.

\subsection{Perception of prevalence rate}

Respondents indicated what percentage of the U.S. adult population they believe eats one of the three diets using a 0-100 slider. This question was used to speak to food norms. It assessed perceptions versus reality to determine whether respondents underestimated or overestimated the proportion of adherents to the three diets. This in turn indicates whether they believe it is more or less "normal" to eat the diets than it truly is. The question wording was based loosely on research on the proportion of immigrants among the population by Ipsos MORI (2014).

\subsection{Social ties}

Participants indicated to what extent they have strong and extensive ties to people who eat one of the diets on a 1 (not at all) to 5 (very great extent) scale. This measure was used to assess food norms and levels of social support. The subject of social ties among vegetarians has been addressed by others including Maclnnis and Hodson (2015, p. 6) who inquired about how many vegetarians or vegans participants knew personally.

\subsection{Theory of planned behavior}

Under the theory of planned behavior (TPB), the probability that an individual will engage in a behavior that is aligned with an attitude is related to how strong their intention is, which can by predicted in three ways: attitude toward the behavior, perceived behavioral control, and subjective norms (Bordens \& Horowitz, 2001, pp. 199-200). The theory holds that "an individual's decision to choose one behavior over another where the behavior is volitional (i.e. under the individual's complete control) will predict whether or not he or she will carry out that behavior" (Povey, Wellens, and Conner, 2001, p. 16). The TPB is considered valuable in forecasting intentions and behaviors in a variety of contexts, including diet (Yadav \& Pathak, 2016, p. 123).

Researchers have used this theory to determine which variables predict intentions to continue to adhere to a vegetarian diet (Cron \& Pobocik, 2013, p. A-90).

\subsection{Behavioral intentions}

Respondents indicated whether they intend to continue eating their diet in the future on a 1 (strongly disagree) to 5 (strongly agree) scale. Other scholars have used the TPB to assess behavioral intentions towards changing meat consumption (Berndsen \& van der Pligt, 2004), eating a vegetarian diet (Povey et al., 2001), and reducing meat consumption (Truelove \& Parks, 2012). 


\subsection{Attitudes}

Participants rated their overall feelings towards one of the diets on four scales: 1 (bad) to 5 (good); 1 (harmful) to 5 (beneficial); 1 (unpleasant) to 5 (pleasant); and 1 (unenjoyable) to 5 (enjoyable). The question wording was based on the work of Povey et al. (2001, p. 19). A reliability analysis with the attitude items was run giving a Cronbach's $a=0.88$, which indicates good reliability and there were no items that if deleted would have increased the scale's reliability.

\subsection{Perceived behavioral control}

Participants indicated their degree of perceived behavioral control for following or continuing to follow one of the three diets for three items: the degree of personal control on a 1 (no control) to 5 (complete control) scale; extent of capability on a 1 (not at all capable) to 5 (very capable) scale; and level of ease or difficulty on a 1 (very difficult) to 5 (very easy) scale. The question wording was based on the work of Povey et al. (2001, p. 19). A reliability analysis with the three items was run giving a Cronbach's $a=0.87$, which indicates good reliability. There were no items that if deleted would have increased the scale's reliability.

\subsection{Subjective norms}

Participants indicated their degree of subject norms using the following items: the extent to which the important people in their life think they should eat the diet on a 1 (not at all) to 5 (to a very great extent) scale; and how much they want to eat what the important people in their life think they should on a 1 (not at all) to 5 (very much) scale. The question wording was based loosely on the work of Povey et al. (2001, p. 19), including creating a subjective norm measure by multiplying the two items together, which resulted in a variable with a range from 1 to $25(M=3.4, S D=3.6)$.

\subsection{Barriers}

Participants indicated their level of agreement on a 1 (strongly disagree) to 5 (strongly agree) scale with six items connected to barriers: 1) It is inconvenient for me to eat a [diet type]; 2) My [diet type] creates issues in my social and personal life; 3) My [diet type] is good for my health; 4) It costs too much to eat a [diet type]; 5) It is difficult for me to stay motivated enough to eat a [diet type]; and 6) I see a [diet type] as part of my identity. The items were based on previous work by Asher et al. (2014). Reverseworded items were inverted prior to analysis.

\subsection{Length of diet adherence}

Respondents indicated their best approximation for how long they had been eating their diet without interruption. They were asked to specify the number of years, months, and days when applicable, or whatever level of detail they could recall. Ranges for adherence were not used as has been done elsewhere (Haverstock \& Forgays, 2012) because it was the average length that was of interest.

Because respondents manually entered the number of years, months, and/or days they had adhered to their diet, there were some out of range values. In all instances, the length of adherence data was excluded from analysis (marked as missing) to prevent taking too many liberties with imputation. These represent a very small proportion of cases. The average number of years was computed using the following formula: years + (months / 12) + (days / 365). 


\section{Results}

\subsection{Demographics}

Table 1 shows the demographic breakdown of the three diet groups as well as whether the differences were statistically significant. The demographic characteristics of an approximation of the full U.S. sample are also reported. There was a significant effect of diet group on average age, $F(2,9286)=18.154, p<0.001$, which corresponds to an effect size of $r=0.06$, a small effect. The age range for vegetarians was smallest (18 to 81 years), with the largest spread for meat reducers (18 to 94 years). There were significant associations between the diet group and all the remaining demographic characteristics: age $\chi^{2}(10)=47.983, p<0.001$, Cramer's $V=0.05$ (a very small effect); sex $\chi^{2}(2)=24.691, p<0.001$, Cramer's $V=0.05$ (a very small effect); region $\chi^{2}(6)=$ 17.497, $p<0.01$, Cramer's $V=0.03$ (a very small effect); education $\chi^{2}(6)=20.295, p<$ 0.01 , Cramer's $V=0.03$ (a very small effect); race/ethnicity $\chi^{2}(8)=78.016, p<0.001$, Cramer's $V=0.06$ (a very small effect); and household income $\chi^{2}(12)=24.354, p<$ 0.05 , Cramer's $V=0.04$ (a very small effect).

Table 1. Demographic characteristics of the three diet groups and the U.S. population from the weighted cleaned sample leaving the screener

\begin{tabular}{|c|c|c|c|c|c|c|}
\hline \multicolumn{2}{|c|}{ Demographic characteristics } & $\begin{array}{l}\mathrm{V} \\
(n= \\
294)\end{array}$ & $\begin{array}{l}\mathrm{R} \\
(n= \\
8,736)\end{array}$ & $\begin{array}{l}\mathrm{C} \\
(n= \\
259)\end{array}$ & $\begin{array}{l}\text { Sig. (chi-sq. } \\
\text { unless } \\
\text { indicated) }\end{array}$ & $\begin{array}{l}\text { U.S. } \\
\text { pop } \\
(n= \\
26,466)\end{array}$ \\
\hline \multicolumn{2}{|c|}{ Average age } & 42.2 & 46.4 & 51.2 & $* * *($ ANOVA $)$ & 47.1 \\
\hline \multicolumn{2}{|c|}{ Age (range) } & $18-81$ & $18-94$ & $18-91$ & - & $18-98$ \\
\hline \multirow[t]{6}{*}{ Age (\%) } & $18-24$ & 18.4 & 12.7 & 13.1 & $* \star *$ & 11.1 \\
\hline & $25-34$ & 21.8 & 20.0 & 8.9 & & 17.7 \\
\hline & $35-44$ & 16.0 & 15.2 & 13.5 & & 16.6 \\
\hline & $45-54$ & 15.6 & 14.8 & 15.1 & & 17.7 \\
\hline & $55-64$ & 13.9 & 17.1 & 17.8 & & 17.3 \\
\hline & $65+$ & 14.3 & 20.1 & 31.7 & & 19.6 \\
\hline \multirow[t]{2}{*}{$\operatorname{Sex}(\%)$} & Female & 63.7 & 50.7 & 58.5 & $\star * *$ & 52.3 \\
\hline & Male & 36.3 & 49.3 & 41.5 & & 47.7 \\
\hline \multirow{4}{*}{$\begin{array}{l}\text { Region } \\
(\%)\end{array}$} & Northeast & 19.0 & 18.7 & 21.6 & ** & 18.1 \\
\hline & South & 30.8 & 37.5 & 35.9 & & 37.3 \\
\hline & Midwest & 26.8 & 18.3 & 15.8 & & 21.4 \\
\hline & West & 23.4 & 25.6 & 26.6 & & 23.2 \\
\hline \multirow[t]{4}{*}{$\begin{array}{l}\text { Education } \\
(\%)\end{array}$} & $\begin{array}{l}\text { Less than 12th } \\
\text { grade, no diploma }\end{array}$ & 5.4 & 8.8 & 7.3 & ** & 7.9 \\
\hline & $\begin{array}{l}\text { High school } \\
\text { diploma (or } \\
\text { equivalent) }\end{array}$ & 12.2 & 17.1 & 17.7 & & 18.4 \\
\hline & $\begin{array}{l}\text { Some education } \\
\text { after high school, } \\
\text { no degree }\end{array}$ & 31.0 & 31.0 & 23.8 & & 32.6 \\
\hline & College degree & 51.4 & 43.1 & 51.2 & & 41.1 \\
\hline
\end{tabular}




\begin{tabular}{|c|c|c|c|c|c|c|}
\hline \multicolumn{2}{|c|}{ Demographic characteristics } & \multirow{2}{*}{$\begin{array}{l}\mathrm{V} \\
(n= \\
294)\end{array}$} & \multirow{2}{*}{$\begin{array}{l}\mathrm{R} \\
(n= \\
8,736)\end{array}$} & \multirow{2}{*}{$\begin{array}{l}C \\
(n= \\
259)\end{array}$} & \multirow{2}{*}{$\begin{array}{l}\text { Sig. (chi-sq. } \\
\text { unless } \\
\text { indicated) }\end{array}$} & \multirow{2}{*}{$\begin{array}{l}\text { U.S. } \\
\text { pop } \\
(n= \\
26,466)\end{array}$} \\
\hline & $\begin{array}{l}\text { (associate, } \\
\text { bachelor's, } \\
\text { master's, or } \\
\text { doctorate) }\end{array}$ & & & & & \\
\hline \multirow{5}{*}{$\begin{array}{l}\text { Race/ } \\
\text { ethnicity } \\
(\%)\end{array}$} & Hispanic & 15.6 & 19.2 & 12.3 & *** & 15.1 \\
\hline & $\begin{array}{l}\text { African American } \\
\text { or Black }\end{array}$ & 5.8 & 15.9 & 10.4 & & 11.7 \\
\hline & Asian & 16.0 & 6.8 & 6.5 & & 5.6 \\
\hline & White & 58.8 & 56.0 & 66.9 & & 65.4 \\
\hline & $\begin{array}{l}\text { Other race/ } \\
\text { ethnicity (including } \\
\text { two or more) }\end{array}$ & 3.7 & 2.1 & 3.8 & & 2.2 \\
\hline \multirow{7}{*}{$\begin{array}{l}\text { House- } \\
\text { hold } \\
\text { Income } \\
(\%)\end{array}$} & $\$ 14,999$ or less & 10.2 & 10.3 & 8.8 & * & 8.8 \\
\hline & $\begin{array}{l}\$ 15,000 \text { to } \\
\$ 24,999\end{array}$ & 5.1 & 8.8 & 10.0 & & 8.6 \\
\hline & $\begin{array}{l}\$ 25,000 \text { to } \\
\$ 34,999\end{array}$ & 4.1 & 8.4 & 7.7 & & 8.8 \\
\hline & $\begin{array}{l}\$ 35,000 \text { to } \\
\$ 49,999\end{array}$ & 13.6 & 12.3 & 9.6 & & 12.5 \\
\hline & $\$ 50,000$ to $\$ 74,999$ & 15.3 & 17.0 & 14.2 & & 17.9 \\
\hline & $\$ 75,000$ to $\$ 99,999$ & 12.9 & 12.8 & 14.2 & & 13.1 \\
\hline & $\$ 100,000$ or over & 38.8 & 30.4 & 35.4 & . & 30.3 \\
\hline
\end{tabular}

A visual inspection of Table 1 suggests that in comparison to meat reducers or chicken avoiders, vegetarians tend to be younger, are more likely to be female, are more likely to live in the Midwest and less likely to live in the South, are better educated, are more likely to be Asian and less likely to be African American or Black, and are more likely to live in a household with a higher income.

\subsection{Prevalence rates}

A third $(33.0 \%)$ of American adults self-identify as reducing their meat consumption, compared to one percent each who identify as a vegetarian $(1.1 \%)$ or a chicken avoider $(1.0 \%) .^{5}$

${ }^{5}$ Population estimates from the United States Census Bureau for the resident population 18 years and over for the U.S. (the focus of the survey sample) for October 2016 (the month the 


\subsection{SWFL}

There was a significant effect for one of the pairs, with a vegetarian diet having the highest level of SWFL: vegetarian diet > reduced-meat diet, vegetarian diet = chicken-free diet, chicken-free $=$ reduced-meat diet. See Table 2.

Table 2. ANOVAs and pairwise comparisons for the three diet groups

\begin{tabular}{|c|c|c|c|c|c|c|c|c|c|c|c|}
\hline \multirow[t]{2}{*}{ Variables } & \multicolumn{2}{|l|}{ V } & \multicolumn{2}{|l|}{$\mathrm{R}$} & \multicolumn{2}{|l|}{$\mathrm{C}$} & \multicolumn{4}{|c|}{ Omnibus test } & \multirow[t]{2}{*}{ Pairs } \\
\hline & $n$ & $\begin{array}{l}M \\
(S D)\end{array}$ & $n$ & $\begin{array}{l}M \\
(S D)\end{array}$ & $n$ & $\begin{array}{l}M \\
(S D)\end{array}$ & $d f$ & $F$ & $p$ & $r$ & \\
\hline SWFL $† \perp$ & 293 & $\begin{array}{l}3.84 \\
(0.69)\end{array}$ & 319 & $\begin{array}{l}3.67 \\
(0.61)\end{array}$ & 249 & $\begin{array}{l}3.72 \\
(0.71)\end{array}$ & $\begin{array}{l}2, \\
859\end{array}$ & 5.436 & $\begin{array}{l}0.00 \\
5\end{array}$ & $\begin{array}{l}0.11 \\
(\mathrm{~s})\end{array}$ & $\begin{array}{l}\mathrm{V}>\mathrm{R}, p= \\
0.004 \\
\mathrm{~V}=\mathrm{C}, p= \\
0.115 \\
\mathrm{C}=\mathrm{R}, p= \\
0.672\end{array}$ \\
\hline $\begin{array}{l}\text { Social ties } \ddagger \\
\S\end{array}$ & 284 & $\begin{array}{l}3.50 \\
(1.37)\end{array}$ & 312 & $\begin{array}{l}2.62 \\
(1.12)\end{array}$ & 246 & $\begin{array}{l}2.33 \\
(1.42)\end{array}$ & $\begin{array}{l}2, \\
526\end{array}$ & $\begin{array}{l}55.20 \\
7\end{array}$ & $\begin{array}{l}0.00 \\
0\end{array}$ & $\begin{array}{l}0.36 \\
(\mathrm{~m})\end{array}$ & $\begin{array}{l}\mathrm{V}>\mathrm{R}, p= \\
0.000 \\
\mathrm{~V}>\mathrm{C}, p= \\
0.000 \\
\mathrm{R}>\mathrm{C}, p= \\
0.029\end{array}$ \\
\hline $\begin{array}{l}(\mathrm{TPB}) \\
\text { Intentions } \ddagger \\
\S\end{array}$ & 284 & $\begin{array}{l}4.85 \\
(0.57)\end{array}$ & 312 & $\begin{array}{l}3.73 \\
(0.90)\end{array}$ & 246 & $\begin{array}{l}4.47 \\
(1.04)\end{array}$ & $\begin{array}{l}2, \\
503\end{array}$ & $\begin{array}{l}168.3 \\
02\end{array}$ & $\begin{array}{l}0.00 \\
0\end{array}$ & $\begin{array}{l}0.49 \\
(\mathrm{~m})\end{array}$ & $\begin{array}{l}\mathrm{V}>\mathrm{C}, p= \\
0.000 \\
\mathrm{~V}>\mathrm{R}, p= \\
0.000 \\
\mathrm{C}>\mathrm{R}, p= \\
0.000\end{array}$ \\
\hline $\begin{array}{l}(\mathrm{TPB}) \\
\text { Attitudes } \ddagger \S\end{array}$ & 284 & $\begin{array}{l}4.83 \\
(0.38)\end{array}$ & 312 & $\begin{array}{l}3.81 \\
(0.80)\end{array}$ & 246 & $\begin{array}{l}4.20 \\
(0.93)\end{array}$ & $\begin{array}{l}2, \\
463\end{array}$ & $\begin{array}{l}230.9 \\
92\end{array}$ & $\begin{array}{l}0.00 \\
0\end{array}$ & $\begin{array}{l}0.51 \\
\text { (I) }\end{array}$ & $\begin{array}{l}\vee>\mathrm{C}, p= \\
0.000 \\
\mathrm{~V}>\mathrm{R}, p= \\
0.000 \\
\mathrm{C}>\mathrm{R}, p= \\
0.000\end{array}$ \\
\hline $\begin{array}{l}\text { (TPB) } \\
\text { Perceived } \\
\text { behavioral } \\
\text { control } \ddagger \S\end{array}$ & 284 & $\begin{array}{l}4.83 \\
(0.38)\end{array}$ & 309 & $\begin{array}{l}3.78 \\
(0.86)\end{array}$ & 246 & $\begin{array}{l}4.77 \\
(0.64)\end{array}$ & $\begin{array}{l}2, \\
490\end{array}$ & $\begin{array}{l}191.2 \\
60\end{array}$ & $\begin{array}{l}0.00 \\
0\end{array}$ & $\begin{array}{l}0.59 \\
\text { (I) }\end{array}$ & $\begin{array}{l}\mathrm{V}=\mathrm{C}, p= \\
0.405 \\
\mathrm{~V}>\mathrm{R}, p= \\
0.000 \\
\mathrm{C}>\mathrm{R}, p= \\
0.000\end{array}$ \\
\hline $\begin{array}{l}\text { (TPB) } \\
\text { Subjective } \\
\text { norms } \ddagger \S\end{array}$ & 284 & $\begin{array}{l}8.83 \\
(7.22)\end{array}$ & 308 & $\begin{array}{l}10.17 \\
(7.55)\end{array}$ & 246 & $\begin{array}{l}6.07 \\
(6.31)\end{array}$ & $\begin{array}{l}2, \\
554\end{array}$ & $\begin{array}{l}25.51 \\
8\end{array}$ & $\begin{array}{l}0.00 \\
0\end{array}$ & $\begin{array}{l}0.23 \\
(\mathrm{~s})\end{array}$ & $\begin{array}{l}\mathrm{R}=\mathrm{V}, p= \\
0.070 \\
\mathrm{R}>\mathrm{C}, p= \\
0.000 \\
\mathrm{~V}>\mathrm{C}, p= \\
0.000\end{array}$ \\
\hline $\begin{array}{l}\text { Convenience } \\
\ddagger \S\end{array}$ & 284 & $\begin{array}{l}3.95 \\
(1.14)\end{array}$ & 308 & $\begin{array}{l}3.35 \\
(1.25)\end{array}$ & 241 & $\begin{array}{l}4.08 \\
(1.20)\end{array}$ & $\begin{array}{l}2, \\
541\end{array}$ & $\begin{array}{l}28.66 \\
5\end{array}$ & $\begin{array}{l}0.00 \\
0\end{array}$ & $\begin{array}{l}0.26 \\
\text { (s) }\end{array}$ & $\begin{array}{l}\mathrm{C}=\mathrm{V}, p= \\
0.394\end{array}$ \\
\hline
\end{tabular}

bulk of the data was collected) were needed to answer this question. However, at the time of analysis, the bureau did not yet have estimates for the population 18 years of age or older as of October 1, 2016. This was instead calculated using available estimates (United States Census Bureau, 2016a; United States Census Bureau, 2016b). 


\begin{tabular}{|c|c|c|c|c|c|c|c|c|c|c|c|}
\hline \multirow[t]{2}{*}{ Variables } & \multicolumn{2}{|l|}{ V } & \multicolumn{2}{|l|}{$\mathrm{R}$} & \multicolumn{2}{|l|}{$C$} & \multicolumn{4}{|c|}{ Omnibus test } & \multirow[t]{2}{*}{ Pairs } \\
\hline & $n$ & $\begin{array}{l}M \\
(S D)\end{array}$ & $n$ & $\begin{array}{l}M \\
(S D)\end{array}$ & $n$ & $\begin{array}{l}M \\
(S D)\end{array}$ & $d f$ & $F$ & $p$ & $r$ & \\
\hline & & & & & & & & & & & $\begin{array}{l}\mathrm{C}>\mathrm{R}, p= \\
0.000 \\
\mathrm{~V}>\mathrm{R}, p= \\
0.000\end{array}$ \\
\hline $\begin{array}{l}\text { Social/perso } \\
\text { nal life } \ddagger \S\end{array}$ & 284 & $\begin{array}{l}3.61 \\
(1.17)\end{array}$ & 308 & $\begin{array}{l}3.72 \\
(1.09)\end{array}$ & 241 & $\begin{array}{l}4.07 \\
(1.05)\end{array}$ & $\begin{array}{l}2, \\
543\end{array}$ & $\begin{array}{l}12.21 \\
8\end{array}$ & $\begin{array}{l}0.00 \\
0\end{array}$ & $\begin{array}{l}0.17 \\
(\mathrm{~s})\end{array}$ & $\begin{array}{l}\mathrm{C}>\mathrm{R}, p= \\
0.000 \\
\mathrm{C}>\mathrm{V}, p= \\
0.000 \\
\mathrm{R}=\mathrm{V}, p= \\
0.491\end{array}$ \\
\hline Health $\ddagger \S$ & 284 & $\begin{array}{l}4.64 \\
(0.61)\end{array}$ & 308 & $\begin{array}{l}4.15 \\
(0.84)\end{array}$ & 241 & $\begin{array}{l}3.92 \\
(1.10)\end{array}$ & $\begin{array}{l}2, \\
500\end{array}$ & $\begin{array}{l}59.26 \\
1\end{array}$ & $\begin{array}{l}0.00 \\
0\end{array}$ & $\begin{array}{l}0.33 \\
(\mathrm{~m})\end{array}$ & $\begin{array}{l}\mathrm{V}>\mathrm{R}, p= \\
0.000 \\
\mathrm{~V}>\mathrm{C}, p= \\
0.000 \\
\mathrm{R}>\mathrm{C}, p= \\
0.019\end{array}$ \\
\hline Cost $\ddagger \S$ & 284 & $\begin{array}{l}4.06 \\
(1.07)\end{array}$ & 308 & $\begin{array}{l}3.29 \\
(1.18)\end{array}$ & 241 & $\begin{array}{l}4.23 \\
(0.98)\end{array}$ & $\begin{array}{l}2, \\
550\end{array}$ & $\begin{array}{l}57.94 \\
2\end{array}$ & $\begin{array}{l}0.00 \\
0\end{array}$ & $\begin{array}{l}0.36 \\
(\mathrm{~m})\end{array}$ & $\begin{array}{l}\mathrm{C}=\mathrm{V}, p= \\
0.135 \\
\mathrm{C}>\mathrm{R}, p= \\
0.000 \\
\mathrm{~V}>\mathrm{R}, p= \\
0.000\end{array}$ \\
\hline $\begin{array}{l}\text { Motivation ¥ } \\
\S\end{array}$ & 284 & $\begin{array}{l}4.67 \\
(0.73)\end{array}$ & 308 & $\begin{array}{l}3.23 \\
(1.24)\end{array}$ & 241 & $\begin{array}{l}4.55 \\
(0.88)\end{array}$ & $\begin{array}{l}2, \\
531\end{array}$ & $\begin{array}{l}157.6 \\
79\end{array}$ & $\begin{array}{l}0.00 \\
0\end{array}$ & $\begin{array}{l}0.56 \\
(\mathrm{I})\end{array}$ & $\begin{array}{l}\mathrm{V}=\mathrm{C}, p= \\
0.219 \\
\mathrm{~V}>\mathrm{R}, p= \\
0.000 \\
\mathrm{C}>\mathrm{R}, p= \\
0.000\end{array}$ \\
\hline Identity $\ddagger \S$ & 284 & $\begin{array}{l}4.18 \\
(1.09)\end{array}$ & 308 & $\begin{array}{l}2.81 \\
(1.11)\end{array}$ & 241 & $\begin{array}{l}3.58 \\
(1.29)\end{array}$ & $\begin{array}{l}2, \\
528\end{array}$ & $\begin{array}{l}114.5 \\
42\end{array}$ & $\begin{array}{l}0.00 \\
0\end{array}$ & $\begin{array}{l}0.45 \\
(I)\end{array}$ & $\begin{array}{l}\mathrm{V}>\mathrm{C}, p= \\
0.000 \\
\mathrm{~V}>\mathrm{R}, p= \\
0.000 \\
\mathrm{C}>\mathrm{R}, p= \\
0.000\end{array}$ \\
\hline
\end{tabular}

Omnibus test: + One-way ANOVA, $\ddagger$ Welch's one-way ANOVA; Pairwise comparisons: $\perp$ Hochberg's GT2, $\S$ Games-Howell. $V=$ vegetarian diet, $R=$ reduced-meat diet, $C=$ chicken-free diet. $s=$ small, $m=$ medium, $I=$ large

\subsection{Social ties}

There was a significant effect for all pairs, with a vegetarian diet performing best on social ties, which indicates that these respondents were most likely to report that they have strong and extensive ties to people who eat the same diet: vegetarian diet $>$ reduced-meat diet $>$ chicken-free diet.

\subsection{Intentions}

There was a significant effect for all pairs, with a vegetarian diet having the highest level of dietary maintenance intentions: vegetarian diet $>$ chicken-free diet $>$ reduced-meat diet. 


\subsection{Attitudes}

There was a significant effect for all pairs, with a vegetarian diet having the highest levels of positive attitudes towards the diet: vegetarian diet $>$ chicken-free diet $>$ reduced-meat diet.

\subsection{Perceived behavioral control}

There was a significant effect for two of the pairs, with a vegetarian diet and a chicken-free diet having the highest perceived behavioral control, which relates to personal control, capability, and the perceived ease or difficulty respondents feel they have over continuing to follow their diet in future: vegetarian diet $=$ chicken-free diet $>$ reduced-meat diet.

\subsection{Subjective norms}

There was a significant effect for two of the pairs, with a reduced-meat diet and a vegetarian diet having the highest scores for subjective norms, which relates to whether the important people in respondents' life think they should eat their diet and to what extent they want to eat what the important people in their life think they should): reduced-meat diet $=$ vegetarian diet $>$ chicken-free diet .

\subsection{Convenience}

There was a significant effect for two of the pairs, with a chicken-free diet and a vegetarian diet having the highest scores for convenience, indicating that these respondents had the least concern that it is inconvenient for them to eat their diet: chicken-free diet $=$ vegetarian diet $>$ reduced-meat diet .

\subsection{Social/personal life}

There was a significant effect for two of the pairs, with a chicken-free diet having the best score on social/personal life experiences, indicating that these respondents had the least concern that their diet creates issues in their social and personal life: chicken-free diet $>$ reduced-meat diet $=$ vegetarian diet .

\subsection{Health}

There was a significant effect for all pairs, with a vegetarian diet having the best score on health experiences, indicating that these respondents were most likely to report that their diet was good for their health: vegetarian diet $>$ reduced-meat diet $>$ chicken-free diet.

\subsection{Cost}

There was a significant effect for two of the pairs, with a chicken-free diet and a vegetarian diet having the best scores for cost experiences, indicating that these respondents were the least concerned that it costs too much to eat their diet: chickenfree diet $=$ vegetarian diet $>$ reduced-meat diet.

\subsection{Motivation}

There was a significant effect for two of the pairs, with a vegetarian diet and a chicken-free diet having the highest scores on motivation, indicating that these respondents were least likely to say it is difficult for them to stay motivated enough to eat their diet: vegetarian diet $=$ chicken-free diet $>$ reduced-meat diet. 


\subsection{Identity}

There was a significant effect for all pairs, with a vegetarian diet having the highest score for identity experiences, indicating that these respondents were more likely to say that they see their diet as part of their identity: vegetarian diet > chickenfree diet $>$ reduced-meat diet.

\subsection{Perception of prevalence rate}

Chicken avoiders believe their diet is 23 times more prevalent among American adults than it is. They believe that more than a fifth $(23.3 \%)$ of U.S. adults consume the diet while the real figure is $1.0 \%$. This was the biggest difference among the three diet groups, though the gap between the perceived and actual rate for vegetarianism (19 times) was also notable. The estimate for meat reducers was close to the actual figure (1.2 times).

\subsection{Length of diet adherence}

Chicken avoiders have the longest self-reported diet adherence (23.6 years), followed by vegetarians (19.5 years). Meat reducers report adhering to their diet for a notably shorter time (4.9 years).

\subsection{Overall findings}

While the reduced-meat diet had the highest prevalence rate, the vegetarian diet had the strongest lived experiences among American adults who are currently eating one of the three meat-restricted diets. See Table 3.

Table 3. Diets' ranking on indicators

\begin{tabular}{ll}
\hline Indicator & Standout diet \\
\hline SWFL & Vegetarian diet \\
Social ties & Vegetarian diet \\
Intentions & Vegetarian diet \\
Attitudes & Vegetarian diet \\
Perceived behavioral control & Vegetarian diet \& chicken-free diet \\
Subjective norms & Reduced-meat diet \& vegetarian diet \\
Convenience & Chicken-free diet \& vegetarian diet \\
Social/personal life & Chicken-free diet \\
Health & Vegetarian diet \\
Cost & Chicken-free diet \& vegetarian diet \\
Motivation & Vegetarian diet \& chicken-free diet \\
Identity & Vegetarian diet \\
Perception of prevalence rate & Chicken-free diet \\
Length of diet adherence & Chicken-free diet \\
\hline
\end{tabular}

\subsection{Chicken avoidance}

Among chicken avoiders, around half $(50.8 \%)$ are pescetarians, while close to another half (45.4\%) have some red meat in their diet-eating (at least) beef or porkand a remaining $3.9 \%$ of chicken avoiders follow a different dietary pattern. The motivations for chicken avoidance were: ethical motivations and taste preferences, followed by health concerns. 


\section{Discussion}

\subsection{Prevalence rates}

Meat reducers are an important and under-studied segment of the population given that to date the literature has focused on vegetarians rather than the potentially influential population of meat reducers. This study found meat reducers to be a larger group than researchers previously imagined-they notably overshadow vegetarians and chicken avoiders in the U.S. population. This may give meat reducers an advantage in terms of modeling consumption norms and increasing demand for meatfree fare. A third of American adults self-identify as meat reducers suggests that this may be a powerful group to harness in terms of shifting customs around food.

However, in many ways vegetarianism, despite its much smaller prevalence, is more rooted in mainstream consciousness than meat reduction and so it is not enough to examine prevalences in isolation without considering how public values and ideas are changing and how collective identities and subcultures are forming in response. Greenebaum has written about a similar pattern for veganism, noting that "although only 1 million people ( 0.5 percent) in the United States follow a vegan diet, veganism has become more prominent in US culture, particularly in its dietary and culinary aspects" (2012, p. 130).

\subsection{Lived experiences}

A possible explanation for why vegetarians report better experiences with their diet is that they have a strong resolve due to the degree to which their diet is restrictive and thus necessitates positive associations to persist. Vegetarians may have spent time learning how to be successful on their diet given its higher demands. Being further along on this learning curve may impart a feeling of control over continued adherence. Indeed, Boyle has shown that early vegetarians, without the necessary coping mechanisms are "still learning the how and the why of the vegetarian way" (2011, p. 321) and similar to other types of behavior change "there should be a learning curve in which people will only acquire more information in order to participate in the lifestyle more effectively" (2011, p. 330). Sticking with this learning curve may be a marker of the strength of one's convictions. As Edwards notes, "the fact that those who have chosen to be vegetarian or vegan are willing to deal with the added anxiety and stress of living in a majority meat-eating society may indicate the strength of their feelings surrounding food and eating" (2013, p. 118). Future research should examine whether there are differences in the levels of determination experienced by vegetarians, meat reducers, and chicken avoiders to help explain if this is one of the mechanisms that underpins vegetarians' different lived experiences.

Another future research direction relates to whether the true lived experience is indeed better for vegetarians or if this is a function of skewed perceptions or perhaps denial. Because of the way food consumption is woven into our social fabric, Boyle explains that "those who practice vegetarianism must negotiate their decision to participate in behavior outside the norm in similar ways to other people who engage in alternative behaviors" (2011, p. 329). Being situated outside of the mainstream is challenging when it comes to eating, given that it is a daily and inherently social activity (Paisley, et al., 2008, p. 80). However, it is possible that vegetarianism's position outside mainstream society is less daunting for current adherents who have actively worked to overcome obstacles and may hold a strong resolve for their dietary choices. 
The finding that meat reducers ranked the lowest on lived experiences is surprising in some ways, especially given the inherent flexibility of the diet. While vegetarianism is said to fall "outside of the accepted eating patterns in Western nations" (Boyle, 2011, p. 314), a reduced meat diet does not position its adherents as far outside mainstream society when it comes to eating and its followers come into less conflict with social food norms than more restrictive dietary patterns like vegetarianism. Yet meat reducers' personal experiences may not be felt as deeply as vegetarians'. Perhaps it is a case of the less sacrifice and need to work to overcome the learning curve, the fewer personal rewards. This is a research question that would benefit from future scholarly attention.

\subsection{Chicken avoidance}

One of the novel contributions of the study is that it offers the first insights about chicken avoidance, which is meaningful considering that this diet speaks to the issue of smaller-bodied animals. This study provides the first reliable estimate of the proportion of chicken avoiders among the U.S. adult population. It is noteworthy that these individuals represent roughly the same proportion of the U.S. adult population as vegetarians, yet far less is discussed in mainstream culture about chicken avoiders or even pescetarians who make up half of all chicken avoiders. This study showed that among chicken avoiders, around half $(50.8 \%)$ are pescetarians, while close to another half $(45.4 \%)$ have some red meat in their diet-eating (at least) beef or pork-and a remaining $3.9 \%$ of chicken avoiders follow a different dietary pattern. This research is believed to be the first to offer insights on the impetus for chicken avoidance: ethical motivations and taste preferences, followed by health concerns.

Overall, chicken avoidance performed better than a reduced-meat diet, which suggests it may have some unexplored potential. One hypothesis for why is that a notable proportion of chicken avoiders are near-vegetarians due to the high prevalence of pescetarianism among the group, which may allow them to share similar personal and social understandings of their dietary life. This research is also believed to be the first to offer insights on the impetus for chicken avoidance.

\subsection{Limitations}

There are limitations to this study that could be addressed in future research. One limitation is the discrepancy in diet data for meat reducers, where-when using the transformed FFQ variable - they self-reported eating more daily servings of meat than expected (for more on this see Asher, 2016a). This speaks to the limits of self-reported dietary recall data. The way meat reducers were operationalized may have also contributed to this limitation because of the high reliance on self-identification.

There are limitations that come from using an online opt-in nonprobability-based sample with population targets, particularly when making inferences about the distribution of variables in society. Future research could attempt to replicate the results of this study using a probability-based online sample considered to be representative of the U.S. population. The weighting procedure, the data cleaning conducted postweighting, and the randomization process also bring potential limitations. Shortcomings may also stem from the use of self-reported data, notably the behavioral intentions question. 


\subsection{Conclusions}

This research contributes to the advancement of scholarly knowledge by providing the first comparative data on a vegetarian diet, a reduced-meat diet, and a chicken-free diet. The study showed that meat reducers are a larger group than previously suspected with a third of American adults self-identifying as reducing their meat consumption, compared to one percent each who identify as a vegetarian or chicken avoider. The findings also demonstrated that a vegetarian diet had the strongest lived dietary experiences among American adults who are currently eating one of these meat-restricted diets. This research speaks to how the degree and type of meat restriction can impact an individual's lived experience with their diet. The study's results show that far more than nutrition and the need to satisfy hunger determine dietary experiences.

\section{Acknowledgements}

The authors would like to thank Dr. Elizabeth Cherry and Dr. Gary Bowden for their contributions to this work as well as many individuals in the Department of Sociology at the University of New Brunswick. They would also like to thank the many individuals who provided feedback on the research during the design phase.

\section{Funding sources and declaration of interest}

This work was supported by the Social Sciences and Humanities Research Council, University of New Brunswick, New Brunswick Innovation Foundation, VegFund, and a fiscal sponsorship managed by Faunalytics. Grantors had no role in the research process. Declarations of interest: none.

\section{References}

Academy of Nutrition and Dietetics. (2016). Position of the academy of nutrition and dietetics: Vegetarian diets. Journal of the Academy of Nutrition and Dietetics, 116(12), 1970-1980.

Adams, C. J. (2004). The pornography of meat. New York, NY: Continuum.

Asher, K. (2016a). Doctoral dissertation - Is the perfect the enemy of the good? The role of dietary choices, perceptions, and experiences in changing meat consumption patterns in the U.S. Retrieved from https://osf.io/vhjem

Asher, K. (2016b). Public registration. Doctoral dissertation - Is the perfect the enemy of the good? The role of dietary choices, perceptions, and experiences in changing meat consumption patterns in the U.S. Retrieved from https://osf.io/rhfqa/

Asher, K., \& Cherry, E. (2015). Home is where the food is: Barriers to vegetarianism and veganism in the domestic sphere. Journal for Critical Animal Studies, 13(1), $66-91$.

Asher, K., Green, C., Gutbrod, H., Jewell, M., Hale, G., \& Bastian, B. (2014). Study of current and former vegetarians and vegans: Companion to the initial findings. Olympia, WA. Retrieved from https://faunalytics.org/wpcontent/uploads/2015/06/Faunalytics_Current-Former-Vegetarians_TablesMethodology.pdf

Beardsworth, A., \& Keil, T. (1992). The vegetarian option: Varieties, conversions, motives and careers. The Sociological Review, 40(2), 253-293.

Berinsky, A. J., Margolis, M. F., \& Sances, M. W. (2014). Separating the shirkers from the workers? Making sure respondents pay attention on self-administered surveys. 
American Journal of Political Science, 58(3), 739-753.

Berndsen, M., \& van der Pligt, J. (2004). Ambivalence towards meat. Appetite, 42(1), 71-8.

Bordens, K. S., \& Horowitz, I. A. (2001). Social psychology (second edition). Mahwah, N.J.: Lawrence Erlbaum Associates.

Boyle, J. E. (2011). Becoming vegetarian: The eating patterns and accounts of newly practicing vegetarians. Food and Foodways, 19(4), 314-333.

Canadian Insitutes of Health Research, Natural Sciences and Engineering Research Council of Canada, \& Social Sciences and Humanities Research Council of Canada. (2014). TCPS2 2-14. Tri-Council policy statement: Ethical conduct for research involving humans. Ottawa, ON. Retrieved from http://www.pre.ethics.gc.ca/pdf/eng/tcps2-2014/TCPS_2_FINAL_Web.pdf

Cherry, E. (2015). I was a teenage vegan: Motivation and maintenance of lifestyle movements. Sociological Inquiry, 85(1), 55-74.

Chiu, T. H. T., \& Lin, C.-L. (2009). Ethical management of food systems: Plant based diet as a holistic approach. Asia Pacific Journal of Clinical Nutrition, 18(4), 647653.

Christensen, G. (2016). Manual of best practices in transparent social science research. Berkeley, CA. Retrieved from http://www.bitss.org/education/manual-of-bestpractices/

Cron, J., \& Pobocik, R. (2013). Intentions to continue vegetarian dietary patterns: An application of the theory of planned behavior. Journal of the Academy of Nutrition and Dietetics, 113(9), A90.

DeMello, M. (2012). Animals and society: An introduction to human-animal studies. New York, NY: Columbia University Press.

Dillard, J. (2008). A slaughterhouse nightmare: Psychological harm suffered by slaughterhouse employees and the possibility of redress through legal reform. Georgetown Journal on Poverty Law \& Policy, XV(2), 391-408.

Dunayer, J. (2004). Speciesism. Derwood, MD: Ryce Publishing.

Edwards, S. (2013). Living in a minority food culture: A phenomenological investigation of being vegetarian/vegan. Phenomenology \& Practice, 7(1), 111-125.

Eshel, G., Martin, P. A., \& Bowen, E. E. (2010). Land use and reactive nitrogen discharge: Effects of dietary choices. Earth Interactions, 14(21), 1-15.

Field, A. (2009). Discovering statistics using SPSS (third edition). Los Angeles, CA: SAGE Publications, Inc.

Food and Agriculture Organization of the United Nations. (2006). Livestock's long shadow: Environmental issues and options. Rome, Italy. https://doi.org/10.1007/s10666-008-9149-3

Fox, N., \& Ward, K. (2008). Health, ethics and environment: A qualitative study of vegetarian motivations. Appetite, 50(2-3), 422-429.

Germov, J., \& Williams, L. (2008). A sociology of food \& nutrition: The social appetite (third edition). Oxford, UK: Oxford University Press.

Greenebaum, J. (2012). Veganism, identity and the quest for authenticity. Food, Culture \& Society, 15(1), 129-144.

Groves, R. M., Fowler, F. J., Couper, M. P., Lepkowski, J. M., Singer, E., \& Tourangeau, R. (2009). Survey methodology (second edition). Hoboken, NJ: John Wiley \& Sons.

Grunert, K. G., Dean, M., Raats, M. M., Nielsen, N. A., \& Lumbers, M. (2007). A measure of satisfaction with food-related life. Appetite, 49(2), 486-493. 
Hatkoff, A. (2009). The inner world of farm animals: Their amazing social, emotional, and intellectual capacities. New York, NY: Stewart, Tabori and Chang.

Haverstock, K., \& Forgays, D. K. (2012). To eat or not to eat. A comparison of current and former animal product limiters. Appetite, 58(3), 1030-1036.

Hirschler, C. A. (2011). "What pushed me over the edge was a deer hunter": Being vegan in North America. Society \& Animals, 19(2), 156-174.

Human Rights Watch. (2004). Blood, sweat, and fear: Workers' rights in U.S. meat and poultry plants. New York, NY. Retrieved from http://www.hrw.org/sites/default/files/reports/usa0105.pdf

Ipsos MORI. (2014). Perceptions are not reality: Things the world gets wrong. Retrieved from https://www.ipsosmori.com/researchpublications/researcharchive/3466/Perceptions-are-not-realityThings-the-world-gets-wrong.aspx

Jabs, J., Sobal, J., \& Devine, C. M. (2000). Managing vegetarianism: Identities, norms and interactions. Ecology of Food and Nutrition, 39(5), 375-394.

Juan, W., Yamini, S., \& Britten, P. (2015). Food intake patterns of self-identified vegetarians among the U.S. population, 2007-2010. Procedia Food Science, 4, 86-93.

Lewis, S. (1994). An opinion on the global impact of meat consumption. American Journal of Clinical Nutrition, 59(5), 1099S-1102S.

MacClellan, J. (2013). Size matters: Animal size, contributory causation, and ethical vegetarianism. Journal of Animal Ethics, 3(1), 57-68.

MacInnis, C. C., \& Hodson, G. (2015). It ain't easy eating greens: Evidence of bias toward vegetarians and vegans from both source and target. Group Processes \& Intergroup Relations, 1-24.

Marlow, H. J., Hayes, W. K., Soret, S., Carter, R. L., Schwab, E. R., \& Sabaté, J. (2009). Diet and the environment: Does what you eat matter? American Journal of Clinical Nutrition, 89(suppl), 1699S-703S.

Messina, G. (2011). Bad news for red meat is bad news for chickens. Retrieved from http://www.theveganrd.com/2011/08/bad-news-for-red-meat-is-bad-news-forchickens.html

Moussaieff Masson, J. (2003). The pig who sang to the moon: The emotional world of farm animals. New York, NY: Ballantine Books.

Nibert, D. (2002). Animal rights/human rights: Entanglements of oppression and liberation. Lanham, MD: Rowman \& Littlefield Publishers, Inc.

NutritionQuest. (n.d.). Meat questionnaire. Retrieved from http://www.nutritionquest.com/products/LLNL_Meat_FFQ_2005.pdf

Oxfam America. (2015). Lives on the line: The human cost of cheap chicken. https://doi.org/10.3898/136266210792307069

Paisley, J., Beanlands, H., Goldman, J., Evers, S., \& Chappell, J. (2008). Dietary change: What are the responses and roles of significant others? Journal of Nutrition Education and Behavior, 40(2), 80-88.

Pimentel, D., \& Pimentel, M. (2003). Sustainability of meat-based and plant-based diets and the environment. The American Journal of Clinical Nutrition, 78(suppl), 660S6635 .

Povey, R., Wellens, B., \& Conner, M. (2001). Attitudes towards following meat, vegetarian and vegan diets: An examination of the role of ambivalence. Appetite, $37(1), 15-26$.

Regan, T. (1983). The case for animal rights. Berkeley, CA: University of California 
Press.

Reijnders, L., \& Soret, S. (2003). Quantification of the environmental impact of different dietary protein choices. American Journal of Clinical Nutrition, 78(suppl), 664S668 S.

Robbins, J. (2001). The food revolution: How your diet can help save your life and our world. Berkeley, CA: Conari Press.

Ruby, M. B. (2012). Vegetarianism. A blossoming field of study. Appetite, 58(1), 14150.

Safran Foer, J. (2009). Eating animals. New York, NY: Little, Brown and Company.

Schnettler, B., Denegri, M., Miranda, H., Sepúlveda, J., Orellana, L., Paiva, G., \& Grunert, K. G. (2015). Family support and subjective well-being: An exploratory study of university students in Southern Chile. Social Indicators Research, 122(3), 833-864.

Simon, D. R. (2013). The meatonomic\$ index. Retrieved from http://meatonomics.com/2013/08/22/meatonomics-index/

Singer, P. (1990). Animal liberation. New York, NY: Avon.

Singer, P., \& Mason, J. (2006). The ethics of what we eat. Why our food choices matter. London, UK: Rodale.

Tomasik, B. (2007). How much direct suffering is caused by various animal foods? Retrieved from http://reducing-suffering.org/how-much-direct-suffering-is-causedby-various-animal-foods/

Truelove, H. B., \& Parks, C. (2012). Perceptions of behaviors that cause and mitigate global warming and intentions to perform these behaviors. Journal of Environmental Psychology, 32(3), 246-259.

Twigg, J. (1983). Vegetarianism and the meanings of meat. In A. Murcott (Ed.), The Sociology of food and eating: Essays on the sociological significance of food ( $\mathrm{pp}$. 18-30). Hants, England: Gower Publishing Company Limited.

United States Census Bureau. (2016a). Estimates of the total resident population and resident population age 18 years and older for the United States, States, and Puerto Rico: July 1, 2016. Retrieved from https://www2.census.gov/programssurveys/popest/tables/2010-2016/state/detail/SCPRC-EST2016-18+POP-RES.xIsx

United States Census Bureau. (2016b). Monthly population estimates for the United States: April 1, 2010 to December 1, 2017 (NA-EST2016-01). Retrieved from https://www2.census.gov/programs-surveys/popest/tables/20102016/national/totals/na-est2016-01.xIsx

University of New Brunswick. (2011). University policy on research involving humans. Retrieved from http://es.unb.ca/apps/policy-repository/_resources/php/downloadpolicy.php?id=YZqi

Yadav, R., \& Pathak, G. S. (2016). Intention to purchase organic food among young consumers: Evidences from a developing nation. Appetite, 96, 122-128. 